\title{
BMJ Open Demographic, lifestyle and comorbid risk factors for all-cause mortality in a Danish cohort of middle-aged adults with incident asthma
}

\author{
Oliver Djurhuus Tupper (D) , ${ }^{1}$ Zorana Jovanovic Andersen, ${ }^{2}$ Charlotte Suppli Ulrik ${ }^{1,3}$
}

To cite: Tupper OD, Andersen ZJ, Ulrik CS. Demographic, lifestyle and comorbid risk factors for allcause mortality in a Danish cohort of middle-aged adults with incident asthma. BMJ Open 2021;11:e049243. doi:10.1136/ bmjopen-2021-049243

- Prepublication history for this paper is available online. To view these files, please visit the journal online (http://dx.doi. org/10.1136/bmjopen-2021049243).

Received 04 February 2021 Accepted 08 September 2021

A) Check for updates

(c) Author(s) (or their employer(s)) 2021. Re-use permitted under CC BY-NC. No commercial re-use. See rights and permissions. Published by BMJ.

${ }^{1}$ Department of Respiratory Medicine, Hvidovre Hospital, Hvidovre, Denmark

${ }^{2}$ Section of Environmental Health, University of Copenhagen Department of Public Health, Kobenhavn, Denmark

${ }^{3}$ Institute of Clinical Medicine, University of Copenhagen, Copenhagen, Denmark

Correspondence to Dr Oliver Djurhuus Tupper; olivertupper@gmail.com

\section{ABSTRACT}

Objective We aimed to identify factors associated with all-cause mortality in adults with incident asthma.

Design and setting Cross-sectional cohort study, in the metropolitan areas of Copenhagen and Aarhus, Denmark. Participants Adults aged 50-64 years enrolled in the Danish Diet, Cancer, and Health cohort were followed up from baseline (1993-1997) in the National Patients Registry for first-time admissions for asthma and vital status. We defined incident asthma as at least one firsttime hospital admission with asthma as the primary registered diagnosis between baseline and end of follow-up (2013) in participants without previously known asthma. Among the cohort comprising 57053 individuals, we identified 785 adults (aged 50 -64) with incident asthma, of whom 76 died during follow-up.

Primary and secondary outcome measures Baseline reported socioeconomic and lifestyle traits, and comorbidities associated with all-cause mortality.

Results Self-reported leisure-time physical activity was associated with a substantial reduction in risk with an HR of 0.53 (95\% Cl 0.33 to 0.85$)$. Being male, single and having a diagnosis of hypertension or diabetes were associated with an increased risk of all-cause mortality with an HR of 1.83 (95\% Cl 1.14 to 2.38), 2.16 (95\% Cl 2.06 to 4.40$), 2.47$ (95\% Cl 1.54 to 3.95$)$ and of 2.42 (95\% $\mathrm{Cl} 0.96$ to 6.11), respectively.

Conclusions This long-term study of adults with hospital contacts for incident asthma revealed that self-reported leisure-time physical activity is associated with an approximately $50 \%$ reduction in all-cause mortality. In contrast, both hypertension and diabetes were associated with a higher risk of mortality.

\section{INTRODUCTION}

With over 300 million persons worldwide suffering from asthma and many deaths each year, asthma is a disease that continually requires attention. ${ }^{12}$ Asthma remains a disease that carries increased mortality compared with general populations. ${ }^{34}$

Asthma-specific mortality has, overall, been on a steady decline since the 1950s..$^{5-7}$ However, a study based on the WHO Mortality Database found that mortality trends have

\section{Strengths and limitations of this study}

- The present study is one of very few reporting on how physical activity and comorbidities are associated with all-cause mortality in adults with asthma.

- Seven hundred eighty-five persons with incident asthma were followed up for 20 years, with no loss to follow-up.

- The diagnosis of asthma is based on registry information and not a verified objective assessment.

- There are only very few events among those with previous myocardial infarction and stroke.

plateaued, with no significant change in mortality between 2006 and 2012. ${ }^{8}$ Furthermore, a British report from 2014 reported that over $67 \%$ of deaths related to asthma were potentially preventable. ${ }^{9}$

Asthma-specific mortality alone does not provide the whole picture when evaluating the risks of the disease for individual patients. A study assessing deaths with asthma as a contributing factor, in addition to asthma-specific causes, found that asthma as a contributing factor was associated with more than twice as many deaths compared with asthma-specific deaths alone. ${ }^{10}$ Studies suggest that patients with asthma are more prone to acquire other chronic conditions than the background population. ${ }^{11-13}$ As the impact of factors such as multimorbidity on all-cause mortality is an area with a paucity of data, there is a need for further studies within this area. ${ }^{14}$ The association between physical activity and long-term mortality has been well established in the general population and among patients with chronic obstructive pulmonary disease (COPD)..$^{15}$ However, this has not been examined extensively in asthma. ${ }^{17}$ The impact of physical activity on asthma-specific factors, such as disease control, lung function and exacerbations, has been well researched. ${ }^{17}$ 
Based on the currently available knowledge, it remains of utmost importance to further explore factors associated with asthma-related mortality, including not least allcause mortality.

The present study aimed to examine demographic, lifestyle and comorbid factors associated with long-term all-cause mortality in adults with incident asthma from a large Danish cohort.

\section{METHODS}

Characteristics of the Diet, Cancer, and Health (DCH) cohort have been published previously, with a full description of the cohort. ${ }^{18} 19$ A total of 160725 individuals (72 729 women) were invited to participate in the DCH cohort between 1993 and 1997. All individuals resided in either Copenhagen or Aarhus, which are the two largest cities in Denmark. To be invited, participants had to be 50-64 years of age and have no record of cancer at the time of inclusion. A total of 57053 individuals (52.4\% women, $\mathrm{n}=29875)$ were enrolled in the study after accepting the invitation. Baseline factors were determined based on a comprehensive questionnaire completed by the participants. The questionnaire consisted of questions on general health and diet; demographic factors, including education and occupation; questions on lifestyle, including tobacco exposure; and pre-existing diseases, including asthma, OPD, diabetes and cardiovascular disease.

\section{Study cohort}

Participants in the DCH cohort were defined as having incident asthma and included in the present analyses as cases if they had the first-ever admission to a hospital, emergency department, or outpatient clinic with a primary diagnosis of asthma, which occurred between cohort baseline (1993-1997) and July first, 2013. Asthma was classified according to the International Classification of Diseases (ICD) as ICD-10 codes DJ45-46 and ICD-8 codes 493.00-493.09. Participants with a self-reported diagnosis of asthma or COPD at baseline were excluded. Participants in the DCH cohort were linked to the Danish National Patient Registry (DNPR) to extract hospital contacts from $1993-1997$ to 1 July $2013 .{ }^{20}$ The link between the DCH and DNPR was done using the unique identifier all Danish residents have. Every discharge diagnosis from all Danish hospitals since 1978 and outpatient clinics since 1995 is gathered in the DNPR. ${ }^{21}$ In addition to hospital contacts, we obtained emergency room visits and visits to respiratory outpatient clinics. Cases were followed up from first-ever asthma admission until the time of death, emigration, or 1 July 2013, whichever came first.

Physical activity in leisure time was determined based on a participant's completed questionnaire. An interviewer checked the questionnaire. Participants reported the number of hours per week they did leisure time and transport-related (ie, to and from work, shopping) physical activity. Leisure-time physical activity was reported separately for summer and winter of the previous year. It was allocated in the following categories: cycling, 'do-ityourself" activities (ie, home improvements), gardening, housework (cleaning, laundry), sports and walking. The two values for summer and winter were averaged. The questions used have previously been validated in two studies by Peters $e t a l^{22}$ and Cust $e t a l^{23}$ that found high correlations with movement sensing measurement and accelerometer measurements, respectively. Participants reported as being physically active in leisure time spent at least half an hour a week on at least one of the six categories.

\section{Statistical analyses}

Associations between baseline factors and all-cause mortality were examined using the Cox proportional hazards model with age as the underlying time scale. We examined the following baseline factors identified at recruitment between 1993 and 1999: age, sex, body mass index (BMI), length of education, employment and civil status, tobacco history, occupational exposure, leisuretime physical activity, fruit consumption and comorbidities. Baseline factors were assessed in a two-step process. Step 1 was in a univariate model, with age as the underlying time scale. Step two was in a multivariate model that included only variables associated with all-cause mortality, defined by backward elimination. The proportional hazards assumption was evaluated by testing for a nonzero slope in a generalised linear regression of the scaled Schoenfeld residuals on functions of time. The univariate and multivariate model results are presented as HRs with $95 \%$ CIs. Stata V.11.2 was used to perform statistical analyses.

\section{Patient and public involvement}

Patients and the public were not involved in the design of the study.

\section{RESULTS}

We identified 785 adults with an incident diagnosis of asthma and by that fulfilling the criteria for inclusion in the present analyses. No individuals were lost to follow-up, and therefore complete data were available for all 785 individuals. All characteristics included in the following analyses were obtained at baseline.

Between baseline and 1 July 2013, 76 of the identified adults with incident asthma died. The majority of cases with incident asthma were women $(63 \%, n=495)$. Only $45 \%(\mathrm{n}=351)$ were never smokers at baseline. Interestingly, a substantial proportion of ever-smokers were ex-smokers $(60 \%, \mathrm{n}=260)$ and not current smokers $(40 \%$, $\mathrm{n}=174$ ). The amount of tobacco exposure was much higher among those who died than those with incident asthma still alive at the end of follow-up. Persons who died had an average daily tobacco usage of $3.8 \mathrm{~g}$ of tobacco, corresponding to $72 \%$ more than those alive at the end 
Table 1 Baseline characteristics of 785 adults enrolled in the Danish diet, cancer and health cohort with incident asthma between baseline (1993-1997) and follow-up (July 2013)

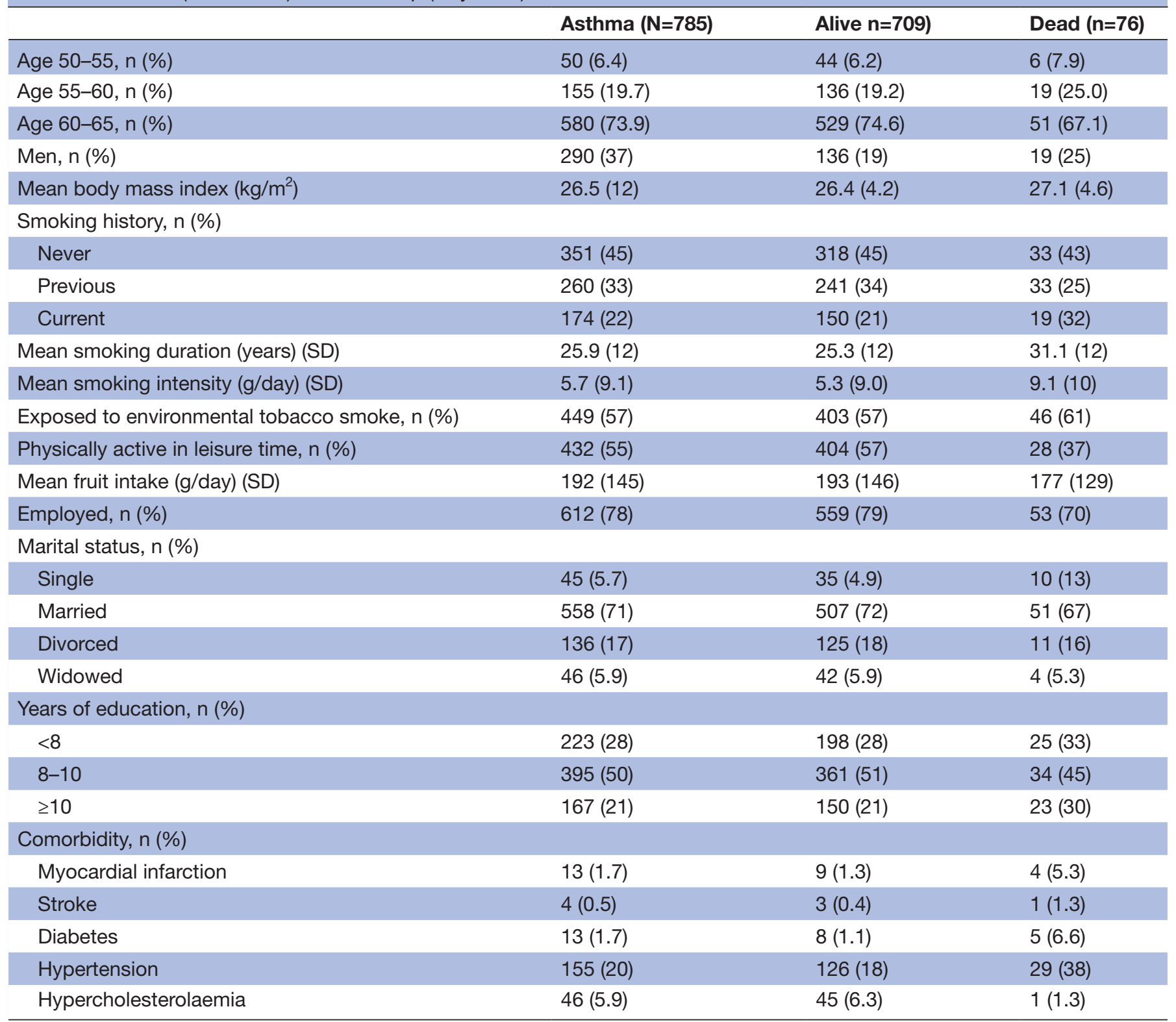

SD, Standard Deviation.

of follow-up. Those who died had a daily intake of fruit that was $16 \mathrm{~g}$ (or $8.3 \%$ ) less than those still alive. Further characteristics are shown in table 1.

Of the baseline characteristics included in the analyses, the following were found to be associated with allcause mortality and were therefore included in the final model: (1) sex, (2) smoking status, (3) physical activity in leisure time, (5) employment status, (6) marital status, (7) diabetes and (8) hypertension. On the other hand, age and a previous diagnosis of myocardial infarction or stroke lacked power for precise estimates for all-cause mortality in univariate analyses and were therefore not included in the final model.

Male sex was associated with a higher risk of all-cause mortality (HR 1.83, 95\% CI 1.14 to 2.93 ). Participants who reported being single had a higher mortality risk (HR of $2.1695 \%$ CI 2.06 to 4.40 ) compared with those who reported being married. A diagnosis of hypertension was associated with a substantially increased risk of all-cause mortality (HR 2.47, 95\% CI 1.54 to 3.95). Self-reported previous myocardial infarction and a current diagnosis of diabetes had imprecise estimates associated with all-cause mortality, although, notably, robust associations were detected. We found an HR of 2.87 (95\% CI 1.04 to 7.89) in the univariate model for myocardial infarction. An HR of 2.42 (95\% CI 0.96 to 6.11$)$ for diabetes was found in the multivariate model. We did not find an association between previous stroke and all-cause mortality.

The self-reported leisure-time physical activity showed a substantial reduction in all-cause mortality (HR 0.53, 
Open access

Table 2 Determinants at baseline of survival in 785 adults with incident asthma during follow-up (2013) among participants in the Danish diet, cancer and health cohort

\begin{tabular}{|c|c|c|}
\hline & Univariate model HR $(95 \% \mathrm{Cl})$ & Multivariate model HR $(95 \% \mathrm{Cl})$ \\
\hline $50-55$ & 1.00 & - \\
\hline $60-65$ & 0.76 (0.28 to 2.08$)$ & \\
\hline \multicolumn{3}{|l|}{ Sex } \\
\hline Male & 1.76 (1.12 to 2.75$)$ & 1.83 (1.14 to 2.93$)$ \\
\hline \multicolumn{3}{|l|}{ Body mass index } \\
\hline Underweight/normal $\left(<25 \mathrm{~kg} / \mathrm{m}^{2}\right)$ & 1.00 & - \\
\hline Overweight $\left(25-30 \mathrm{~kg} / \mathrm{m}^{2}\right)$ & 1.56 (0.93 to 2.63$)$ & - \\
\hline Obese $\left(\geq 30 \mathrm{~kg} / \mathrm{m}^{2}\right)$ & 1.52 (0.79 to 2.91$)$ & - \\
\hline Current & 1.64 (0.96 to 2.78$)$ & 1.39 (0.81 to 2.38$)$ \\
\hline \multicolumn{3}{|l|}{ Activity in leisure time } \\
\hline Inactive & 1.00 & 1.00 \\
\hline Active & 0.47 (0.29 to 0.74$)$ & 0.53 (0.33 to 0.85$)$ \\
\hline \multicolumn{3}{|l|}{ Mean fruit intake } \\
\hline g/day & 0.91 (0.76 to 1.07$)$ & - \\
\hline \multicolumn{3}{|l|}{ Employment } \\
\hline Yes & 1.00 & 1.00 \\
\hline No & $1.17(0.70$ to 1.96$)$ & $1.04(0.87$ to 1.25$)$ \\
\hline- & 1.00 & - \\
\hline+ & 2.87 (1.04 to 7.89$)$ & - \\
\hline \multicolumn{3}{|l|}{ Stroke } \\
\hline- & 1.00 & - \\
\hline+ & $1.58(0.22$ to 11.43$)$ & - \\
\hline \multicolumn{3}{|l|}{ Diabetes } \\
\hline- & 1.00 & 1.00 \\
\hline+ & 3.58 (1.44 to 8.90$)$ & 2.42 (0.96 to 6.11$)$ \\
\hline \multicolumn{3}{|l|}{ Hypertension } \\
\hline- & 1.00 & 1.00 \\
\hline+ & 2.57 (1.61 to 4.09 ) & 2.47 (1.54 to 3.95$)$ \\
\hline
\end{tabular}

Cl, Confidence Interval; HR, Hazard Ratio. 
$95 \%$ CI 0.33 to 0.85$)$. Mean daily fruit intake was not found to be associated with death (table 2).

\section{DISCUSSION}

In this Danish cohort of 785 adults with incident asthma followed up for 20 years, we found that physical activity was associated with a lower risk of all-cause mortality. In contrast, being single or having hypertension was associated with increased all-cause mortality.

\section{Physical activity}

To the best of our knowledge, this is the first cohort study that has reported the association between self-reported physical activity and all-cause mortality, specifically in individuals with asthma. Physical activity has previously been shown to have a positive effect on multiple aspects of asthma. ${ }^{17}$ Particularly relevant are two studies by GarciaAymerich $e t a l^{4}$ and Fisher $e t a l^{25}$ that found a protective effect of self-reported physical activity on hospitalisation with asthma exacerbations. While the same effect could not be found on readmissions for exacerbations in the study by Fisher $e t a l,{ }^{25}$ their findings are essential to support our findings, as exacerbations are associated with overall morbidity and mortality. ${ }^{26}$ Physical activity also appears to have a positive effect on asthma control. ${ }^{27}$ However, BMI appears to be more critical, negating the effects of physical activity in some, but not all, models. ${ }^{17}$ It appears that if persons with asthma have a moderate level of physical activity compared with inactivity and strenuous physical activity, asthma control is positively affected. ${ }^{28}$ The positive effects on these other asthma outcomes could support our finding that physical activity is associated with lower mortality risk.

The effects of physical activity are prudent to establish as we know that patients with asthma generally are less physically active than the general population. ${ }^{29}$ Further, we know from a Cochrane review from 2013 that physical activity is well tolerated and safe for individuals with asthma. ${ }^{30}$ The review found that physical activity may improve cardiopulmonary function in individuals with asthma without negatively impacting pulmonary function. Furthermore, the Cochrane review is based on shorter-term studies. Long-term findings from the Copenhagen City Heart study suggest that physical activity may diminish long-term lung function decline in individuals with asthma. ${ }^{31}$ The amount of physical activity required to be defined as physically active in our study is relatively low and, therefore, should be attainable by most. However, future studies should explore whether there are additional benefits from moderate and high levels of activity. Additionally, would a high or very high level of activity mean the risks of adverse outcomes outweigh the benefits? A study by Russell $e t a \ell^{32}$ found that the benefits of physical activity on asthma symptoms were only present at light levels of activity and not at intense activity levels. Based on our findings, there is absolutely reason to motivate persons with asthma to do physical activity in their leisure time.

\section{Sex}

We found that men had a higher HR for early death than women. Our finding of higher all-cause mortality among men with asthma is well in line with what is found by previous studies by Lemmetyinen $e t a \hat{l}^{3}$ and Connolly $e t$ $a l^{34}$ However, because of the way the analyses are carried out, it is likely more a reflection of a general higher mortality among men than specifically asthma-related.

\section{Marital status}

Being single (never married) compared with married showed an independently higher risk of death, while being divorced or widowed showed no change. This effect has been shown repeatedly in previous studies. ${ }^{35} 36$ The reasons behind this effect is still much discussed; partly studies suggest that there is a selection of less robust individuals to remain single or become divorced. Additionally, there also seems to be a protective effect in being married. ${ }^{37}$ A study by Dantzer $e t a l^{88}$ found that there was no difference between single and married individuals with asthma. However, they had not stratified single, as we have done, into three different groups. Therefore, persons who were widowed or divorced were included in the single group. As we found, being widowed or divorced is not associated with all-cause mortality, which may explain the discrepancies in findings.

\section{Comorbidities}

Hypertension had a strong association with death. Overall, all included comorbid conditions at baseline appeared to be associated with a higher risk of death. However, only hypertension had a robust estimate, probably since the remaining comorbidities (diabetes, stroke and myocardial infarction) had a relatively low prevalence at baseline.

There is limited research on how hypertension relates to mortality in a person with asthma. ${ }^{14}$ We found one other study by Sumino $e t a l^{39}$ from 2014 that reported the association between hypertension and mortality. They found a lower OR for mortality among individuals with hypertension over the age of 65 . However, the study by Sumino et $a l^{99}$ had a much shorter follow-up of 3 years compared with the 20 years of our study. Given that hypertension is a condition that gives long-term complications, these complications are likely not caught across such a short period.

While the estimated HR for mortality among those with diabetes was imprecise due to lack of power, it is worth mentioning that there appeared to be a strong association between diabetes and a higher risk of all-cause mortality. While the amount of other studies is exceedingly limited, there is other literature supporting this finding. Sumino et $a l^{39}$ found that diabetes was associated with a higher mortality rate in persons over 65 . Another cohort study by Koskela $e t a l^{0}$ showed that among 110 patients admitted due to an asthma exacerbation, there was a higher risk 
of mortality for those with diabetes. While there is a clear trend in our data towards higher all-cause mortality risk for individuals with previous myocardial infarction, the HR estimate was imprecise once again due to only four events. Nevertheless, an excess risk of mortality due to cardiovascular disease is an area that has substantial data supporting it in asthma cohorts, and this certainly supports our finding. ${ }^{414}$

The factors presented in this paper may seem obvious but needs to be verified in asthma, mainly as many of these factors have not previously been explored concerning adults with asthma; not least in large cohorts, as in the present long-term follow-up study of a large cohort of middle-aged men and women with asthma. The relevance of this is due to the systemic inflammation present in persons with asthma, which potentially could affect and change which factors are essential to be aware of compared with general populations. ${ }^{43} 44$

\section{Limitations}

The diagnosis of asthma in the included subjects was based on International Classification of Diseases, 10th Revision (ICD-10) codes connected to hospital contacts, which is not as accurate as objectively verified asthma. However, this has previously been established by Jensen et $a t^{45}$ to be a robust method of identifying persons with asthma. The positive predictive value was found to be $65 \%$; despite this, they discovered that associations found are still relevant. Selecting only persons with either a hospital or outpatient contact means we may limit generalisability, with the majority of persons included having moderate or severe disease. Nonetheless, a study from 2014 found that upwards of $25 \%$ of asthma patients with mild to moderate disease experience poor asthma control and hospital admissions. ${ }^{46}$

The prevalence of asthma in this cohort is low (about $1 \%$ ), substantially lower than the current reported prevalence in Denmark of 10\%; therefore, the generalisability is limited. The low prevalence is due to including only participants without a previous diagnosis of asthma and only individuals referred to secondary care.

Our definition of physical activity was based on selfreported information, which carries a certain degree of bias. Additionally, a potential limitation is that the degree of self-reported physical activity for some was reported multiple years before the first contact for incident asthma. We can, therefore, not be sure that the level of physical activity still applies at follow-up. However, previous literature suggests that physical activity tracks well over time, particularly in adulthood. ${ }^{474}$

We did not have information on the specific cause of death and could not examine factors relating to asthmaspecific mortality. Furthermore, we did not have data on asthma severity, medication, pulmonary function and previous exacerbation, which influence mortality risk.

As the number of events in this cohort study was not substantial, there is a risk of underestimating and overestimating the importance of the identified risk factors.
Therefore, the results of this study cannot stand on their own, yet provide a valuable source for future studies. This is particularly evident for diabetes, which shows a clear trend for a higher risk of mortality, though it lacks the power for a precise estimate.

\section{CONCLUSIONS}

Our study has shown that for middle-aged individuals with hospital contact for incident asthma, persons with comorbidity or are single are at an increased risk of early all-cause mortality. In contrast, leisure-time physical activity was found to have a protective effect on mortality risk. Our findings, therefore, suggest that it is important to encourage our asthma patients to do physical activity. Future studies should examine how varying levels of physical activity affect mortality in persons with asthma. Is there a diminishing or negative effect at very high levels of activity?

Acknowledgements Thanks to Anne Tjønneland and Kim Overvad for providing us with access to the data from the Diet, Cancer and Health cohort.

Contributors Conception and design: ODT, ZJA and CSU; preparation of data and statistical analyses: ZJA; statistical interpretation and drafting of the manuscript: ODT; all authors: critical review and acceptance of the final version of the manuscript.

Funding The authors have not declared a specific grant for this research from any funding agency in the public, commercial or not-for-profit sectors.

Competing interests None declared.

Patient and public involvement Patients and/or the public were not involved in the design, conduct, reporting or dissemination plans of this research.

Patient consent for publication Not applicable.

Ethics approval The study was approved by the ethical committee for the capital region of Denmark ( $\mathrm{H}-17025043)$, the regional data safety committee for the capital region of Denmark (P-2019-712) and The Danish Data Protection Agency (2014-413468). All participants signed an informed consent form.

Provenance and peer review Not commissioned; externally peer reviewed.

Data availability statement Data are available upon reasonable request. Data analysis may require approval from the regional data safety committee for the capital region of Denmark (Videnscenter for dataanmeldelser).

Open access This is an open access article distributed in accordance with the Creative Commons Attribution Non Commercial (CC BY-NC 4.0) license, which permits others to distribute, remix, adapt, build upon this work non-commercially, and license their derivative works on different terms, provided the original work is properly cited, appropriate credit is given, any changes made indicated, and the use is non-commercial. See: http://creativecommons.org/licenses/by-nc/4.0/.

\section{ORCID iD}

Oliver Djurhuus Tupper http://orcid.org/0000-0002-8788-6726

\section{REFERENCES}

1 WHO. Global surveillance, prevention and control of chronic respiratory diseases: a comprehensive approach, 2007. Available: http://www.who.int/gard/publications/GARD Book 2007.pdf?ua=1

2 Glob. Initiat. Asthma. Global strategy for asthma management and prevention, 2020. Available: https://ginasthma.org

3 Huovinen E, Kaprio J, Vesterinen E, et al. Mortality of adults with asthma: a prospective cohort study. Thorax 1997;52:49-54.

4 D'Amato G, Vitale C, Molino A, et al. Asthma-related deaths. Multidiscip Respir Med 2016;11:1-5.

5 Speizer FE, Doll R, Heaf P. Observations on recent increase in mortality from asthma. Br Med J 1968;1:335-9. 
6 Jackson RT, Beaglehole R, Rea HH, et al. Mortality from asthma: a new epidemic in New Zealand. Br Med J 1982;285:771-4.

7 Sly RM. Mortality from asthma, 1979-1984. J Allergy Clin Immunol 1988;82:705-17.

8 Ebmeier S, Thayabaran D, Braithwaite I, et al. Trends in international asthma mortality: analysis of data from the who mortality database from 46 countries (1993-2012). Lancet 2017;390:935-45.

9 Levy ML. The National review of asthma deaths: what did we learn and what needs to change? Breathe 2015;11:14-24.

10 McCoy L, Redelings M, Sorvillo F, et al. A multiple cause-of-death analysis of asthma mortality in the United States, 1990-2001. J Asthma 2005;42:757-63.

11 Soriano JB, Visick GT, Muellerova H, et al. Patterns of comorbidities in newly diagnosed COPD and asthma in primary care. Chest 2005;128:2099-107.

12 Gershon AS, Wang C, Guan J, et al. Burden of comorbidity in individuals with asthma. Thorax 2010;65:612-8.

13 Adams RJ, Wilson DH, Taylor AW, et al. Coexistent chronic conditions and asthma quality of life: a population-based study. Chest 2006;129:285-91.

14 Marques de Mello L, Cruz Álvaro A, Cruz AA. A proposed scheme to cope with comorbidities in asthma. Pulm Pharmacol Ther 2018;52:41-51.

15 Lear SA, Hu W, Rangarajan S, et al. The effect of physical activity on mortality and cardiovascular disease in 130000 people from 17 highincome, middle-income, and low-income countries: the PURE study. Lancet 2017;390:2643-54

16 Waschki B, Kirsten A, Holz O, et al. Physical activity is the strongest predictor of all-cause mortality in patients with COPD: a prospective cohort study. Chest 2011;140:331-42.

17 Cordova-Rivera L, Gibson PG, Gardiner PA, et al. A systematic review of associations of physical activity and sedentary time with asthma outcomes. J Allergy Clin Immunol Pract 2018;6:1968-81.

18 Tjønneland A, Olsen A, Boll K, et al. Study design, exposure variables, and socioeconomic determinants of participation in diet, cancer and health: a population-based prospective cohort study of 57,053 men and women in Denmark. Scand J Public Health 2007;35:432-41.

19 Bønnelykke K, Raaschou-Nielsen O, Tjønneland A, et al Postmenopausal hormone therapy and asthma-related hospital admission. J Allergy Clin Immunol 2015;135:813-6.

20 Pedersen CB. The Danish civil registration system. Scand J Public Health 2011;39:22-5.

21 Schmidt M, Schmidt SAJ, Sandegaard JL, et al. The Danish national patient registry: a review of content, data quality, and research potential. Clin Epidemiol 2015;7:449.

22 InterAct Consortium, Peters T, Brage S, et al. Validity of a short questionnaire to assess physical activity in 10 European countries. Eur J Epidemiol 2012;27:15-25.

23 Cust AE, Smith BJ, Chau J, et al. Validity and repeatability of the EPIC physical activity questionnaire: a validation study using accelerometers as an objective measure. Int J Behav Nutr Phys Act 2008;5:33.

24 Garcia-Aymerich J, Varraso R, Antó JM, et al. Prospective study of physical activity and risk of asthma exacerbations in older women. Am J Respir Crit Care Med 2009;179:999-1003.

25 Fisher JE, Loft S, Ulrik CS, et al. Physical activity, air pollution, and the risk of asthma and chronic obstructive pulmonary disease. Am J Respir Crit Care Med 2016;194:855-65.

26 Chipps BE, Zeiger RS, Borish L, et al. Key findings and clinical implications from the epidemiology and natural history of asthma: outcomes and treatment regimens (TENOR) study. J Allergy Clin Immunol 2012;130:332-42.
27 Panagiotou M, Koulouris NG, Rovina N. Physical activity: a missing link in asthma care. J Clin Med 2020;9:706.

28 Del Giacco SR, Firinu D, Bjermer L, et al. Exercise and asthma: an overview. Eur Clin Respir J 2015;2:27984.

29 van 't Hul AJ, Frouws S, van den Akker E, et al. Decreased physical activity in adults with bronchial asthma. Respir Med 2016;114:72-7.

$30 \mathrm{Kv} \mathrm{C}, \mathrm{Mg}$ C, Picot J. Physical training for asthma (review) summary of findings for the main comparison. Cochrane Libr 2013:1-73.

31 Garcia-Aymerich J, Lange P, Benet M, et al. Regular physical activity modifies smoking-related lung function decline and reduces risk of chronic obstructive pulmonary disease: a population-based cohort study. Am J Respir Crit Care Med 2007;175:458-63.

32 Russell MA, Janson C, Real FG, et al. Physical activity and asthma: a longitudinal and multi-country study. J Asthma 2017;54:938-45.

33 Lemmetyinen RE, Karjalainen JV, But A, et al. Higher mortality of adults with asthma: a 15-year follow-up of a population-based cohort. Allergy 2018;73:1479-88.

34 Connolly CK, Alcock SM, Prescott RJ. Mortality in asthmatics over 15 yrs: a dynamic cohort study from 1983-1998. Eur Respir J 2002;19:593-8.

35 Farr. The influence of marriage upon the rate of mortality. The Lancet 1879;113:787.

36 Hu YR, Goldman N. Mortality differentials by marital status: an international comparison. Demography 1990;27:233-50 https://www. ncbi.nlm.nih.gov/pubmed/2332088

37 Robards J, Evandrou M, Falkingham J, et al. Marital status, health and mortality. Maturitas 2012;73:295-9.

38 Dantzer C, Tessier JF, Nejjari C, et al. Mortality of elderly subjects with self-reported asthma in a French cohort, 1991-1996. Eur J Epidemiol 2001:17:57-63.

39 Sumino K, O'Brian K, Bartle B, et al. Coexisting chronic conditions associated with mortality and morbidity in adult patients with asthma. J Asthma 2014;51:306-14.

40 Koskela HO, Salonen PH, Romppanen J, et al. A history of diabetes but not hyperglycaemia during exacerbation of obstructive lung disease has impact on long-term mortality: a prospective, observational cohort study. BMJ Open 2015;5:6794.

$41 \mathrm{Xu} \mathrm{M}, \mathrm{Xu}$ J, Yang X. Asthma and risk of cardiovascular disease or all-cause mortality: a meta-analysis. Ann Saudi Med 2017:37:99-105.

42 Strand LB, Tsai MK, Wen CP, et al. Is having asthma associated with an increased risk of dying from cardiovascular disease? A prospective cohort study of 446346 Taiwanese adults. BMJ Open 2018;8:e019992.

43 Denburg JA, Sehmi R, Saito H, et al. Systemic aspects of allergic disease: bone marrow responses. J Allergy Clin Immunol 2000;106:S242-6.

44 Bjermer L. Time for a paradigm shift in asthma treatment: from relieving bronchospasm to controlling systemic inflammation. $J$ Allergy Clin Immunol 2007;120:1269-75.

45 Jensen Annette Østergaard, Nielsen GL, Ehrenstein V. Validity of asthma diagnoses in the Danish national Registry of patients, including an assessment of impact of misclassification on risk estimates in an actual dataset. Clin Epidemiol 2010;2:67-72.

46 von Bülow A, Kriegbaum M, Backer V, et al. The prevalence of severe asthma and low asthma control among Danish adults. J Allergy Clin Immunol Pract 2014;2:759-67.

47 Telama R. Tracking of physical activity from childhood to adulthood: a review. Obes Facts 2009;2:187-95.

48 Mertens E, Clarys P, Mullie P, et al. Stability of physical activity, fitness components and diet quality indices. Eur J Clin Nutr 2017;71:519-24. 